\title{
Population-based survey of HIV sero-status and vertical transmission among naive pregnant women in Sokoto, Nigeria
}

\author{
*Fiekumo Igbida Buseri', Charity Ngozi Okonkwo² \\ ${ }^{1}$ Department of Medical Laboratory Sciences, Faculty of Basic Medical Sciences, College of Health Sciences, Niger Delta University, \\ Wilberforce Island, Bayelsa State, Nigeria, '²Department of Medical Laboratory Sciences, Rivers State University of Science and Technology, \\ Port Harcourt, Nigeria
}

\section{A B S T R A C T}

Background: This study aims at investigating the seroprevalence of HIV infection among status naive pregnant women and probable vertical transmission in Sokoto, Nigeria. Materials and Methods: This cross-sectional study examined 13,026 apparently healthy pregnant women aged between 14 and 45 years and 312 mother-baby pairs in 4 different hospital settings in Sokoto State, North West, Nigeria between March, 2011 and February, 2013. The babies were aged between 8 and 16 months. HIV screening was performed using qualitative rapid tests and ELISA and HIV-DNA polymerase chain reaction (PCR) techniques. Measurement of CD4 + T-lymphocytes was carried out by the BD FACScount System. All seropositive pregnant women were immediately placed on triple antiretroviral therapy (ART) throughout the duration of the pregnancy and beyond. Results: An overall $2.4 \%$ prevalence of HIV-1 infection among the pregnant women and $20.5 \%$ incident of mother-to-child transmission were found. Of the seropositive pregnant women, $75.0 \%$ were full-time house wives, $13.8 \%$ and $11.2 \%$ were traders and civil servants respectively; of which, $70.2 \%$ were within the ages of 14 and 27 years (youthful predominance). Pearson's $\chi^{2}$ analysis did not show any statistically significant difference in the Mean values in the 4 health facilities $\left(\chi^{2}=2.084, \mathrm{df}=3, \mathrm{P}\right.$-value $\left.=0.555\right)$. Similarly, no significant difference in HIV seropositivity in the demographic data of the pregnant women were observed $(P>0.05)$. Infection was recorded in all age groups but there was no statistical significance between age groups and infection ( $P=0.833)$. Of the 64 seropositive babies, $62(92.5 \%)$ contracted HIV from antiretroviral therapy non-adherence mothers $\left(\chi^{2}=271.457, \mathrm{df}=1, \mathrm{P}<0.01\right)$, $\mathrm{OR}=1506.6(95 \% \mathrm{Cl}=285.5-7950.4)$. Conclusion: This study found high prevalence of vertical transmission due to ART non-adherence. Intervention initiatives should, therefore, focus seriously on ART non-adherence.

Key words: HIV-naive pregnant women, Vertical transmission, Nigeria
Access this article online

Website:

http://nepjol.info/index.php/AJMS

DOI: 10.3126/ajms.v6i3.11530

\section{INTRODUCTION}

The greatest health problem threatening the human race in our time is the HIV/AIDS pandemic where the burden is greatest in sub-Saharan Africa. ${ }^{1}$ Epidemiologic data indicates that heterosexual and vertical transmissions constitute $80-95 \%$ of HIV infections in Nigeria. ${ }^{2}$ This is largely influenced by lack of sexual health information and education, ignorance of one's HIV status, socio-cultural practices, poor healthcare system, general poverty, low levels of condom use and high levels of sexually transmitted infections (STIs). ${ }^{3}$ Since the first case of HIV was reported in a 13-year old girl in 1986 in Nigeria, ${ }^{4}$ it is estimated that approximately 3.5 million people are currently living with HIV making Nigeria with the second highest burden of HIV in the world, only after South Africa. ${ }^{1}$ With this figure, it is estimated that the current National HIV seroprevalence in Nigeria as at the end of 2012 is $3.4 \%{ }^{2}$ 
This unfortunate epidemic, which was once dominated by infected males, has become progressively feminized and in sub-Saharan Africa (Nigeria inclusive) approximately $60 \%$ of adults living with HIV are women. ${ }^{1}$ As HIV prevalence increases among women in sub-Saharan Africa and the world in general, the risks of mother-to-child transmission (MTCT) of HIV also increases. MTCT accounts for $90 \%$ of HIV infection among children less than 15 years. ${ }^{1,3}$ With an estimated 260,000 children infected with HIV as at the end of 2011, Nigeria accounts for more than $10 \%$ of the global paediatric HIV burden. ${ }^{5}$ Consequently, a burden has been placed on women and children, who in many settings continue to experience high rates of new HIV infections and of HIV-related illnesses and death (3). The high burden of MTCT in Nigeria is due to high viral load, mode of delivery, prolonged rupture of membranes, prematurity, higher prevalence of HIV in women of reproductive age, high total fertility rate, characteristically prolonged breastfeeding culture, as well as poor access to prevention of mother-to-child transmission (PMTCT) interventions. In the absence of MTCT interventions $20-45 \%$ of infants born to HIV positive women will become positive during pregnancy, delivery, or through breastfeeding. ${ }^{6}$ And childhood HIV has become a critical health problem that threatens to undermine the positive impact of child survival strategies in the African continent.

The possibility that both the pregnant woman and her child could be HIV-infected calls for concerted efforts at establishing the magnitude of the problem in order to achieve the main objective of antenatal care. To promote maternal good health that will lead her to produce live healthy baby at the end of the pregnancy. Any pregnant woman screened positive for HIV will be effectively managed during the antenatal, intrapartum and post-natal periods to help reduce the MTCT rate of HIV. In addition, early diagnosis of HIV infection in pregnancy will make it possible for HIV-exposed and HIV-infected infants to receive early prophylaxis for opportunistic infections and antiretroviral therapy (ART). ${ }^{7}$ If left untreated, HIV infection in children is associated with high morbidity and mortality rates. ${ }^{8}$ Furthermore, a review of the HIV test results in a PMTCT programme will provide a unique opportunity for evaluating the success of the PMTCT programme. ${ }^{7} \mathrm{HIV}$ testing in pregnancy is the gate way to accessing care for the mother and child. The interventions in prevention of mother to child transmission (PMTCT) of HIV can only be applied to a woman whose HIV status is known ${ }^{9}$ through laboratory screening during ante-natal visit. Against this background, this study aims at investigating the seroprevalence of HIV infection among status naive pregnant women and the probable vertical transmission of HIV in four ante-natal clinics in Sokoto State, North West, Nigeria.

\section{MATERIALS AND METHODS}

\section{Study design}

This was a cross-sectional study conducted among antenatal attendees who had counselling on HIV infection and antiretroviral therapy (ART).

\section{Setting}

This study was conducted at four (4) different hospital settings in Sokoto State, Nigeria which include Usman Dan Fodio University Teaching Hospital (UDUTH), a tertiary healthcare institution located in Sokoto, the state capital with 1400 bed capacity; Specialist Hospital Sokoto, a secondary healthcare institution with a bed capacity of 620 also located in the state capital; Dogon-Daji General Hospital, a primary health centre located in Dogon-Daji Local Government area of Sokoto state. It is a rural health centre with 200 bed capacity; and Holy-Family Health Centre, another a primary health centre located in WAMACO Local Government Area of Sokoto state with 100 bed capacity. The 4 hospitals were chosen because they offer free prevention of mother-to-child transmission (PMTCT) of HIV services.

\section{Study population}

A total of 13,026 apparently healthy pregnant women aged between 14 and 45 years who were attending the Antenatal Clinics for the very first time in this their current pregnancy of the above four (4) different hospital settings in Sokoto State were consecutively recruited for this study. Exclusion criteria were history of HIV and knowledge of HIV status. A nurse/midwife counsellor obtained the information on bio-data and socio-demographic parameters.

\section{Informed consent and ethical clearance}

Informed consent was obtained from each pregnant woman prior to sample collection. Ethical approval was obtained from the Medical Ethics Committee of the Hospitals.

\section{Sample collection and analyses}

Two millimetres $(2 \mathrm{ml})$ of venous blood was collected from each participant into EDTA bottles and mixed properly to avoid clotting. All the pregnant women and the motherinfant pairs of the HIV seropositive mothers were screened for human immunodeficiency virus (HIV) antibodies, CD4 count and viral load. All analyses were carried out according to standard procedures. The mothers HIV screening was carried out using Abbott Determine ${ }^{\mathrm{TM}}$ HIV $1 / 2$ test kit (Abbot Laboratories, Illinois, USA), STAT- PAK ${ }^{\mathrm{TM}}$ HIV-1/2 (CHEMBIO Diagnostic System Inc. USA) and Clinotech Diagnostic Enzyme-Linked Immunosorbent Assay (ELISA) test kits (Clinotech Laboratories, USA). The Manufacturers' Standard Operating Procedures (SOPs) 
were strictly followed. Briefly, each pregnant woman's serum was tested for the presence of HIV antibodies using Determine ${ }^{\mathrm{TM}} \mathrm{HIV}-1 / 2$ and STAT- PAK ${ }^{\mathrm{TM}} \mathrm{HIV}-1 / 2$. If both kits tested positive, the result was considered positive for HIV infection. These methods which are immunochromatographic and qualitative in nature, detect the presence of antibodies to HIV-1 and HIV-2 in human blood with a sensitivity of more than $99.9 \%$ and specificity of $99.75 \%$. If the results were discordant, ELISA was used as tie breaker. HIV-seropositivity was defined as a reactive result on two of the test systems. Subjects not reactive were considered HIV-seronegative.

All the HIV exposed infants born to the HIV positive pregnant women were screened for HIV using HIVDNA Polymerase Chain Reaction (PCR) technique on Dried Blood Spot (DBS) samples taken from them using Q1Aamp DNA Mini kit.

Criteria for the pregnant women eligibility for ART initiation (treatment)

The national PMTCT guidelines for pregnant women eligibility for ART initiation was used after adherence counselling. Only those who tested positive for HIV and at or over 14 weeks of gestation and irrespective of their $\mathrm{CD} 4$ cell counts were placed on triple antiretroviral cocktail consisted of Zidovudine (AZT) or Stavudine (D4T) plus Lamivudine (3TC) plus either Nevirapine (NVP) or Efavirenz (EFZ) throughout the duration of the pregnancy and beyond. All the pregnant women who tested positive for HIV were included for the treatment to prevent HIV transmission to their infants. ${ }^{10}$ The entire HIV positive mothers exclusively breastfed their babies until the baby was sampled for screening.

\section{HIV-exposed babies ART regimen}

The HIV-exposed babies (babies born to HIV positive women) were given nevirapine (NVP) and septrin (cotrimoxazole) prophylaxis within the first three days of life up to six weeks. The HIV-exposed infants were thereafter screened for HIV according to the National Early Infant Diagnosis algorithm which stipulates that a DNA
PCR test should be carried out on all HIV-exposed infants at age six weeks. Mothers of infants with a positive HIV result were counselled to enrol the infant into HIV care and treatment services, while those who breastfed and whose babies have a negative HIV results were advised to return six weeks after the complete cessation of breastfeeding for a repeat DNA PCR test. If the HIV-PCR test was negative the initial treatment was suspended, but if the HIV-PCR test was positive they were given a combination dose of zidovudine (AZT), lamivudine (3TC) and nevirapine (NVP). ${ }^{10}$ Combination drug regimens are considered the standard of care for treatment of HIV infection and for prevention of perinatal HIV transmission. ${ }^{10}$

\section{Data analysis}

The data analysis was carried out using Statistical Package for Social Science (SPSS) software (version 17.0, SPSS, Chicago, USA). The level of significance was set at $\mathrm{P}<0.05$. Percentages mean and standard deviations were used for the descriptive data. The results of human immunodeficiency virus (HIV) test were expressed as either positive or negative as the case may be.

\section{RESULTS}

Out of the 13,026 antenatal attendees screened for HIV infection, $12,714(97.6 \%)$ were HIV sero-negative and $312(2.4 \%)$ were HIV sero-positive (all were HIV type-1). Initially, it was 324 out of the 13,026 pregnant women $(2.5 \%)$ who tested positive for HIV infection but $12(3.7 \%)$ relocated their residency and were lost to follow-up. Those 312 HIV positive pregnant women constituted the substudy population, of which $64(20.5 \%)$ transmitted the infection to their babies while the remaining 248 (79.5\%) did not transmit the infection to their babies. Of the 4 health facilities, the antenatal attendees of Dogon-Daji Health Centre had the highest prevalence rate of $5.57 \%$. HIV seropositivity among the babies was also the highest in this health facility. However, analysis of variants (ANOVA) did not show any statistically significant difference among the 4 health facilities $\left(\chi^{2}=2.084, d f=3, P\right.$-value $\left.=0.555\right)$ (Table 1).

\begin{tabular}{|c|c|c|c|c|c|}
\hline \multirow[t]{2}{*}{ Health facility } & \multirow[t]{2}{*}{ Total } & \multicolumn{2}{|c|}{ HIV status of Mothers (\%) } & \multicolumn{2}{|c|}{ HIV status of children of HIV positive Mothers (\%) } \\
\hline & & Pos. & Neg. & Pos. & Neg. \\
\hline Specialist Hospital Sokoto & 4506 & $100(2.22)$ & $4406(97.78)$ & $20(20.00)$ & $80(80.00)$ \\
\hline UDUTH & 5500 & $100(1.82)$ & $5400(98.18)$ & $17(17.00)$ & $83(83.00)$ \\
\hline Holy Family HC & 1520 & $30(1.97)$ & $1490(98.03)$ & $6(20.00)$ & $24(80.00)$ \\
\hline Dogon-Daji HC & 1500 & $82(5.57)$ & $1418(94.53)$ & $21(25.61)$ & $61(74.39)$ \\
\hline Total & 13026 & $312(2.40)$ & $12714(97.6)$ & $64(20.51)$ & $248(79.49)$ \\
\hline
\end{tabular}


Analysis of the demographic data of the pregnant women positive for HIV-1 infection (Table 2a) shows that the majority, 251 (80.4\%) were Muslims and 61 (19.6\%) were Christians. Cross Tabulation Analysis of Religion versus HIV Status indicated that $14(23.0 \%)$ of the HIV-1 seropositive pregnant women were Christians and $50(19.9 \%)$ were Muslims; whereas, $47(77.0 \%)$ and $201(80.1 \%)$ were seronegative, respectively. All the pregnant women positive for HIV infection had formal or Qu'ranic education with $40.7 \%$ of them with secondary education; $75.0 \%$ were house wives while $13.8 \%$ and $11.2 \%$ were traders and civil servants respectively (Tables $2 \mathrm{~b}, \mathrm{c}$ and d). Analysis of variants (ANOVA) did not show any significant difference among the demographic data $(\mathrm{P}>0.05)$ of the HIV seropositive mothers.

\begin{tabular}{lc} 
Table 2a: Frequency distribution of the \\
demographic data of the pregnant women \\
positive for HIV infection \\
\hline Demographic data & Frequency (\%) \\
\hline Religion & $61(19.6)$ \\
Christians & $251(80.4)$ \\
Muslims & $312(100.0)$ \\
Total & \\
Education & $21(6.7)$ \\
Higher institution & $127(40.7)$ \\
Secondary education & $91(29.2)$ \\
Primary education & $73(23.4)$ \\
Qu'ranic education & $312(100.0)$ \\
Total & \\
Occupation & $35(11.2)$ \\
Civil servant & $234(75.0)$ \\
House wife & $43(13.8)$ \\
Trading & $312(100.0)$ \\
Total &
\end{tabular}

\begin{tabular}{|c|c|c|c|}
\hline \multirow[t]{2}{*}{ Religion } & \multicolumn{2}{|c|}{ HIV status } & \multirow[t]{2}{*}{ Total } \\
\hline & + & - & \\
\hline Christian & $14(23.0)$ & $47(77.0)$ & 61 \\
\hline Muslim & 50 (19.9) & $201(80.1)$ & 251 \\
\hline Total & 64 (20.5) & $248(79.5)$ & 312 \\
\hline
\end{tabular}

\begin{tabular}{|c|c|c|c|}
\hline \multirow[t]{2}{*}{ Education } & \multicolumn{2}{|c|}{ HIV status } & \multirow[t]{2}{*}{ Total } \\
\hline & + & - & \\
\hline Higher institution & $1(4.8)$ & $20(95.2)$ & 21 \\
\hline Secondary education & $26(20.5)$ & $101(79.5)$ & 127 \\
\hline Primary education & $20(22.0)$ & $71(78.0)$ & 91 \\
\hline Qu'ranic education & $17(23.3)$ & $56(76.7)$ & 73 \\
\hline Total & $64(20.5)$ & $248(79.5)$ & 312 \\
\hline
\end{tabular}

As shown in Tables 3 and 4 , of the 312 HIV-1 seropositive pregnant women studied, $219(70.2 \%)$ were within the ages of 14 and 27 years; of which $46(21.0 \%)$ were seropositive for HIV-1 and $173(79.0 \%)$ were seronegative. The remaining $93(29.8 \%)$ were 28 years and above; of which $18(19.4 \%)$ were seropositive for HIV-1 and $75(80.6 \%)$ were seronegative; making a total of $64(20.5 \%)$ seropositive for HIV-1 and 248 (79.5\%) seronegative. No maternal age group was free from HIV infection. The babies' sex distribution consisted of $158(50.6 \%)$ males and $154(49.4 \%)$ females. Of the $158(50.6 \%)$ males, $33(20.9 \%)$ were HIV-1 positive and $125(79.1 \%)$ were HIV-1 negative. Of the154 (49.4\%) females, 31 (20.1\%) were HIV-1 positive and $123(79.9 \%)$ were HIV-1 negative. Pearson's $\chi^{2}$ analysis revealed no statistically significant difference between the babies' sex and HIV seropositivity $\left(\chi^{2}=0.027, d f=1\right.$, $P$-value $=0.869)$.

Table 5 shows the frequency distribution of the babies' age groups versus HIV status. Nearly one-third (30.1\%) were aged $8-10$ months, $46.2 \%$ were aged $11-13$ months, and $23.7 \%$ were aged $14-16$ months. The HIV seropositivity cut across all the age groups and there were no statistically significant differences in the proportions $\left(\chi^{2}=1.729, d f=2\right.$, $P$-value $=0.440)$.

Table 6 summarizes the cross tabulation analysis of adherence and non-adherence versus HIV Status. Of the 312 pregnant women positive for HIV-1 infection, $245(78.5 \%)$ adhered to their antiretroviral therapy regimen and the remaining $67(21.5 \%)$ did not adhere. Of the 67 non- adherence cases $62(92.5 \%)$ transmitted the HIV-1

\begin{tabular}{|c|c|c|c|}
\hline \multirow[t]{2}{*}{ Occupation } & \multicolumn{2}{|c|}{ HIV status } & \multirow[t]{2}{*}{ Total } \\
\hline & + & - & \\
\hline Civil servant & $4(11.4)$ & $31(88.6)$ & 35 \\
\hline House wife & $50(21,4)$ & $184(78.6)$ & 234 \\
\hline Trading & $10(23.3)$ & $33(76.7)$ & 43 \\
\hline Total & $64(20.5)$ & $248(79.5)$ & 312 \\
\hline
\end{tabular}

Table 3: Frequency distribution of HIV sero-positivity according to mothers' age groups

\begin{tabular}{lc}
\hline Mothers' age group (years) & Frequency (\%) \\
\hline $14-20$ & $91(29.2)$ \\
$21-27$ & $128(41.0)$ \\
$28-34$ & $61(19.6)$ \\
$35-41$ & $25(8.0)$ \\
41 and above & $7(2.2)$ \\
Total & 312 \\
\hline HIV, human immunodeficiency virus &
\end{tabular}




\begin{tabular}{|c|c|c|c|c|c|c|c|}
\hline \multirow{2}{*}{$\begin{array}{l}\text { Mothers age } \\
\text { group (years) }\end{array}$} & \multicolumn{2}{|c|}{ HIV status } & \multirow[t]{2}{*}{ Total } & \multirow{2}{*}{$\begin{array}{l}\text { Baby } \\
\text { sex }\end{array}$} & \multicolumn{2}{|c|}{ HIV status } & \multirow[t]{2}{*}{ Tota } \\
\hline & + & - & & & + & - & \\
\hline $14-20$ & $22(24.2)$ & $69(75.8)$ & 91 & Male & $33(20.9)$ & $125(79.1)$ & 158 \\
\hline $21-27$ & $24(18.8)$ & $104(81.3)$ & 128 & Female & $31(20.1)$ & $123(79.9)$ & 154 \\
\hline $28-34$ & $11(18.0)$ & $50(82.0)$ & 61 & Total & $64(20.5)$ & $248(79.5)$ & 312 \\
\hline $35-41$ & $5(20.0)$ & $20(80.0)$ & 25 & & & & \\
\hline 41 and above & $2(28.6)$ & $5(71.4)$ & 7 & & & & \\
\hline Total & $64(20.5)$ & $248(79.5)$ & 312 & & & & \\
\hline
\end{tabular}

$\chi^{2}=1.506, \mathrm{df}=4, \mathrm{P}$ value $=0.833, \chi^{2}=0.027, \mathrm{df}=1, \mathrm{P}$ value $=0.869 . \mathrm{HIV}$, human immunodeficiency virus

\begin{tabular}{lccc} 
Table 5: Frequency distribution of the babies' \\
HIV status according to age groups (in months) \\
$\begin{array}{lccc}\text { Babies' age } \\
\text { group (in months) }\end{array}$ & \multicolumn{2}{c}{ HIV status } & Total (\%) \\
\cline { 2 - 3 } & $\mathbf{+}$ & - & \\
\hline $8-10$ & $15(16.0)$ & $79(84.0)$ & $94(30.1)$ \\
$11-13$ & $32(22.2)$ & $112(77.8)$ & $144(46.2)$ \\
$14-16$ & $17(23.0)$ & $57(77.0)$ & $74(23.7)$ \\
Total & $64(20.5)$ & $248(79.5)$ & 312 \\
\hline$\chi^{2}=1.729, \mathrm{df}=2$, P value=0.440. Abbreviation: HIV, human immunodeficiency virus
\end{tabular}

\begin{tabular}{|c|c|c|c|}
\hline \multirow[t]{2}{*}{ ART } & \multicolumn{2}{|c|}{ HIV status } & \multirow[t]{2}{*}{ Total } \\
\hline & + & - & \\
\hline Non -adherence & $62(92.5)$ & $5(7.5)$ & 67 \\
\hline Adherence & $2(0.8)$ & $243(99.2)$ & 245 \\
\hline Total & $64(20.5)$ & 248 (79.5) & 312 \\
\hline
\end{tabular}

$\chi^{2}=271.457, \mathrm{df}=1, \mathrm{P}$ value $=<0.01 ; \mathrm{OR}=1506.6(95 \% \mathrm{Cl}=285 \cdot 5-7950.4) . \mathrm{HIV}$, human immunodeficiency virus

infection to their babies while $5(7.5 \%)$ did not transmit the HIV infection to their babies. Pearson's $\chi^{2}$ analysis revealed a significant difference $(\mathrm{P}<0.05)$ in the transmission rate between those who adhered to their antiretroviral therapy regimen and those who did not adhere. The babies of the HIV positive mothers that did not adhere to their antiretroviral therapy regimen are 1,506.6 times more likely to have HIV infection than the children of the HIV positive mothers that adhered (Odd Ratio $=1506.6$ (95\% CI $=285.5$ 7950.4). Whereas, of the 245 HIV-1 positive pregnant women who adhered to their antiretroviral therapy regimen, only $2(0.8 \%)$ transmitted the HIV-1 infection to their babies; while the remaining $243(99.2 \%)$ did not transmit the HIV infection to their babies $\left(\chi^{2}=271.457, d f=1\right.$, $P$-value $=<0.01) O R=1506.6(95 \% C I=285.5-7950.4)$. In the overall, $64(20.5 \%)$ of the babies were positive for HIV infection and $248(79.5 \%)$ were negative.

Table 7 shows the frequency distribution of the HIV-1 positive pregnant women in relation to adherence and non-adherence versus mother's age groups. Analysis of variants (ANOVA) revealed that maternal age group
Table 7: Frequency distribution of the HIV positive pregnant women in relation to non-adherence and adherence and mother's age groups

\begin{tabular}{lccc}
\hline \multirow{2}{*}{$\begin{array}{l}\text { Mother's } \\
\text { age group }\end{array}$} & \multicolumn{2}{c}{ ART (\%) } & Total \\
\cline { 2 - 3 } & Non compliance & Compliance & \\
\hline $14-20$ & $23(25.3)$ & $68(74.7)$ & 91 \\
$21-27$ & $26(20.3)$ & $102(79.7)$ & 128 \\
$28-34$ & $10(16.4)$ & $51(83.6)$ & 61 \\
$35-41$ & $6(24.0)$ & $19(76.0)$ & 25 \\
41 and above & $2(28.6)$ & $5(71.4)$ & 7 \\
Total & $67(21.5)$ & $245(78.5)$ & 312 \\
\hline$\chi^{2}=2.119, \mathrm{df}=4$, P value $=0.735$. HIV, human immunodeficiency virus \\
\hline
\end{tabular}

did not influence the transmissibility of the HIV-1 infection in relation to adherence and non-adherence to their antiretroviral therapy regimen $\left(\chi^{2}=2.119, d f=4\right.$, $P$-value $=0.735$.

\section{DISCUSSION}

This study found $2.4 \%$ overall prevalence of HIV-1 infection among the pregnant women and 20.5\% prevalence rate of mother-to-child transmission, which could serve as a baseline data and subsequently be used to monitor the trend of the disease. No woman was seropositive to HIV-2, which may suggest that HIV-2 is not common in this locality. Reasons for this current seroprevalence rates include high prevalence of low level of national and individual awareness, low perception to risk, and poverty in the community, and non-adherence. Our findings indicate that HIV infection is still a major public health problem among women of reproductive age and paediatrics in Sokoto, Nigeria. This relatively low 2.4\% seroprevalence obtained in this current study was not very surprising as compared with the $6.4 \%$ prevalence found in the National HIV seroprevalence sentinel survey report of 2012 among the general population of antenatal clinic attendees in Sokoto State. ${ }^{11}$

Our seroprevalence rate in this study is similar to some earlier reports conducted in Nigeria such as the 3.0\% found in Jos, North-Central Nigeria ${ }^{12}$ and the $2.83 \%$ reported by Ajoge et al. ${ }^{13}$ in Okene. However, the $2.4 \%$ seroprevalence rate in 
this study is lower than the $3.5 \%$ seroprevalence found in another related study carried out at the University of Port Harcourt Teaching Hospital, Port Harcourt, South-South Nigeria $;{ }^{14}$ the $4.1 \%$ in Yenagoa City, Bayelsa State. ${ }^{9}$ Similar studies in other parts of Nigeria such as the $5.2 \%$ reported at the Federal Medical Centre, Yola, North-eastern Nigeria, ${ }^{15}$ the $28.6 \%$ reported at University College Hospital, Ibadan, Nigeria ${ }^{16}$ and the $7.8 \%$ at the General Hospital, Minna, Nigeria ${ }^{17}$ all reported higher rates. The $2.4 \%$ seroprevalence in this study is also lower than some similar studies reported from other African countries like in Kenya $(6.7 \%)^{18}$ and Tanzania $(10.6 \%) .{ }^{19}$ This lower rate may suggest a steady decline in HIV-1 infection among pregnant women in general. However, the existence of $2.4 \%$ HIV-1 prevalence still presents a serious public health problem in this state. It poses a special risk in transmitting the infection to their fetuses or infants during pregnancy, labour or breast feeding.

In contrast, the finding in this study is higher than the $0.8 \%$ seroprevalence found in a Missionary Hospital, Nsukka, Nigeria $;{ }^{20}$ whereas, Sahaf et al. ${ }^{21}$ and Todd et al., ${ }^{22}$ found no cases of HIV infection in Malekan and Kabul, respectively. Those various findings succinctly indicate that there is a wide geographical variation in the seroprevalence of HIV infection amongst pregnant women within and outside Nigeria. This corroborates the importance of establishing our own institution based values. The variations may be a reflection of the differences in socio-cultural practices, low perception to risk, and poverty in the community.

The study subjects' demographic data did not affect or influence their HIV status in this our study (occupations: $\chi^{2}=2.075, d f=2, P$-value $=0.354$; religion: $\chi^{2}=0.276$, $d f=1, P$-value $=0.599$ and education: $\chi^{2}=3.660, d f=3$, $P$-value $=0.301)$ [Tables $2 \mathrm{~b}, \mathrm{c}$ and $\mathrm{d}]$. The house wives, civil servants and traders all had their fair share of the HIV infection and the differences were not statistically significant $(\mathrm{P}>0.05)$. Both the Christians and Muslims of the study subjects (pregnant women) were seropositive for HIV-1; it is therefore important to mount a sensitization campaign on the need for voluntary counselling and testing of the spouses to reduce the spread of HIV/AIDS in the general population. The entire pregnant women positive for HIV-1 infection have some level of formal or Qu'ranic education with $40.7 \%$ of them with secondary education. None of the women was an illiterate. This finding is in consonance with the findings of Imade et al., ${ }^{23}$ who reported that literate women had a higher prevalence of HIV infection compared to their illiterate counterparts.

Maternal age groups distribution did not affect HIV seropositivity in our study. All the maternal age groups experienced HIV infection. However, $70.2 \%$ were within the ages of 14 and 27 years. This corroborates the reported higher incidence of sexual activities among the youths (age $<30$ years). Maternal age group did not also affect or influence the seropositivity of HIV among the babies in this study $\left(\chi^{2}=1.506, d f=4, P\right.$-value $\left.=0.833\right)$ [Tables 3 and 4$]$. This is in concert with the findings of Imade et al..$^{23}$

Our current study observed a relatively high incidence/ prevalence of $20.5 \%$ (64/312) mother-to-child transmission (MTCT) of HIV among exclusively breastfed HIV-exposed newborn babies. This corroborates the fact that mother to child transmission of HIV still remains one of the most efficient and prominent ways of paediatric HIV transmission in Nigeria. This finding also gives credence to the need to offer routine screening to all HIV-exposed newborn babies as provided in the $\mathrm{WHO}$ guideline ${ }^{24}$ as well as the need to intensify efforts to get MTCT service to the large numbers of Nigerian women needing it. According to the UNGASS Country Progress Report for Nigeria, ${ }^{25}$ there are about 57,000 babies born with HIV each year and an estimated 360,000 children are living with HIV in Nigeria, most of whom became infected from their mothers. ${ }^{26}$ The MTCT rate in this study is comparable to the $18.5 \%$ at the Nnamdi Azikiwe University Teaching Hospital, Nnewi ${ }^{27}$ and the $22 \%$ reported at the Nigerian Institute of Medical Research, Yaba, Lagos, Nigeria. ${ }^{28}$ It is, however, higher than the $13.6 \%$ reported at the Imo State University Teaching Hospital, Orlu, Imo State ${ }^{29}$ and the $2.54 \%$ at the Amino Kano University Teaching Hospital, Kano. ${ }^{30} \mathrm{It}$ is also higher than the $4.9 \%$ and $12.1 \%$ obtained from Brazil ${ }^{31}$ and $\mathrm{Cuba}^{32}$ respectively. Our MTCT rate is lower than the $45.0 \%$ and $93.3 \%$ at the University College Hospital, Ibadan, Southwestern Nigeria by Odaibo et al., ${ }^{33}$ and Ogubosi et al., ${ }^{34}$ respectively.

Though the finding of $20.5 \%$ in this study is considered high it falls below the often quoted $25-45 \%$ estimated rate of MTCT of HIV without intervention..$^{35}$ It is difficult to ascertain the level of success without control group and there were no previously established baselines in the four healthcare facilities to compare outcomes. This study has provided for the very first time a platform to compare or monitor the efficiency of the antiretroviral therapy (ART) regimens and the general prevention of mother-to-child transmission (PMTCT) of HIV services in the study sites. This notwithstanding, we call for more concerted efforts to improve the services or methodologies to reduce it further to at least less than one per cent $(<1 \%)$. Studies have shown that when HIV-infected women are treated with antiretroviral therapy and their infants receive antiretroviral (ARV) prophylaxis, mother-to-child transmission of HIV (MTCT) occurs in less than $1 \%$ of pregnancies. ${ }^{36,37}$

Some infants became infected despite treatment probably because (a) the HIV transmission occurred before treatment, 
(b) inefficient suppression of maternal viral replication by zidovudine, (c) non-adherence to the treatment regimen, or (d) unique characteristics of the infecting maternal strain of HIV, such as decreased susceptibility to zidovudine. Susceptibility testing of isolates from these motherinfant pairs was not performed. High-level resistance to zidovudine was unlikely, considering the relatively short duration of the maternal treatment, the lack of previous maternal exposure to zidovudine before now, and the relatively high median CD4+ T-lymphocyte count of the mothers at entry. Non-adherence to the treatment regimen is a very strong factor. Of the 67 non-adherence cases, $62(92.5 \%)$ transmitted the HIV infection to their babies.

This study recorded a non-adherence rate of $21.5 \%$ among the HIV-positive pregnant women. This is in consonance with the $21.7 \%$ reported by Igwegbe et a $l^{38}$ in a similar study at Nnewi, Nigeria and the $19.4 \%$ reported by Ekama et al. ${ }^{39}$ in Lagos, Nigeria. It is, however, higher than the $16.3 \%$ reported in Zambia, ${ }^{40}$ but lower than the 37.1\% and $37.4 \%$ reported by Oloowokere et al. ${ }^{41}$ and Shaahu et al., ${ }^{42}$ respectively in Ibadan, Southwestern Nigeria. The $21.5 \%$ non adherence rate found in this study is considered high in spite of the fact that all the women had adherence counseling prior to the initiation of ART. This may indicate a need to review pre commencement adherence counseling practice in the area in terms of organization, content and delivery. It may be important to survey the knowledge of the trained counselors and possibly organize periodic retraining. Proper evaluation of the clients for beliefs and attitudes is central to effective counseling as studies have shown that clarification of clients' beliefs and attitudes during adherence counseling significantly improve their level of adherence to ART. ${ }^{38,43}$

We did not examine the likely causes of the non-adherence and would suggest further research in this direction. But whatever are the likely reasons HIV-positive pregnant women should realize that antiretroviral therapy in pregnancy is not solely for preventing/controlling maternal disease but also to prevent mother-to-child transmission of HIV. Of the 67 non-compliance cases, $62(92.5 \%)$ transmitted the HIV infection to their babies while $5(7.5 \%)$ did not transmit the HIV infection to their babies. Pearson's $\chi^{2}$ analysis revealed a significant difference $(\mathrm{P}<0.05)$ between those who adhered to and those who did not adhere to their antiretroviral therapy regimen. The non-adherence HIV-positive mothers had 1,506.6-fold increase rate of MTCT of HIV in this study $\left(\chi^{2}=271.457\right.$, $d f=1, P$-value $=<0.01 ; O R=1506.6(95 \% C I=285.5-7950.4)$, whereas, Galli et al. ${ }^{44}$ in their cohort study reported that temporary discontinuation led to a 10 -fold increase in the rate of MTCT, overcoming all other risk factors, except for the independent factor of high plasma viral RNA load at delivery. It is important, therefore, to note that temporary discontinuation of ART after commencement or nonadherence is both detrimental to the maternal health.

Adequate adherence to the prescribed antiretroviral medications is essential to achieving maximal viral suppression necessary to prevent MTCT. ${ }^{38}$ Adherence rates exceeding $95 \%$ are necessary, in order to maximize the benefits of antiretroviral therapy. Higher levels of drug adherence are associated with improved virological, immunological, and clinical outcome. ${ }^{45}$ Poor adherence to antiretroviral drugs during pregnancy can lead to suboptimal viral suppression, development of viral resistance, higher risk of mother-to-child transmission, and mother-to-child transmission of resistant HIV strains. ${ }^{46}$ Interrupting medication permits the virus to resume rapid replication and as many as 1010 viral particles will be produced per day. This allows resistant mutant strains to be generated which are no longer responsive to available antiretroviral drugs, posing a public health danger. Adherence to antiretroviral drugs poses unique challenges to HIV infected persons particularly among pregnant women. ${ }^{47}$ Improving adherence among pregnant women therefore requires knowledge of the factors that influence adherence.

The HIV seropositivity among the babies in this study cut across all the age groups in months (Table 7) and there were no statistically significant differences in the proportions in the age groups $\left(\chi^{2}=1.729, d f=2, P\right.$-value $\left.=0.440\right)$ even though those in groups 14-16 months old and 11-13 months old were higher than those in group 8-10 months old, $23 \%$, $22.2 \%$ and $16 \%$ respectively. This is likely to be due to the length of time the babies were exposed to breast feeding as all the mothers were exclusively breast feeding their babies. However, Shaffer et al..$^{48}$ reported a statistically significant difference in children less than 6 months of age who had higher rate of HIV (12.6\%) than children 6-11 months old $(1.9 \%)$ and children $1-13$ years old $(4.1 \%)$.

\section{CONCLUSIONS}

In conclusion, this study has shown a significant incidence of mother to child transmission (MTCT) of HIV, which could now serve as baseline data for subsequent monitoring of MTCT among HIV seropositive antenatal women on ART in Sokoto State. The greatest challenge was non-adherence by some of the seropositive mothers on antiretroviral therapy. Adherence to antiretroviral therapy is a principal predictor for the success of prevention of mother to child transmission of HIV. It is to be recommended that intervention initiatives should focus seriously on ART non-adherence among 
seropositive antenatal attendees. Timely detection of non-adherence behaviours and appropriate monitoring of patients' difficulties with ART could potentially help seropositive antenatal attendees on anti-retroviral therapy to maintain adherence and therefore improve the treatment outcomes. There was no relationship between demographic variables like gender and age range with HIV seropositivity in the babies. It is to be recommended that assess to PMTCT services be scaled up to arrest any chances of mother-to-child-transmission. More so, paediatric HIV treatment services and support should be scaled up to ensure the achievement of a HIV free generation in the nearest future.

\section{ACKNOWLEDGEMENTS}

The authors are grateful to all the mothers and babies, nurse/midwives who participitated in this study and the management of the four health care facilities for their permission to conduct this project.

\section{REFERENCES}

1. UNAIDS 'Global Report 2013'.

2. National Agency for Control of AIDS (NACA): Factsheet 2014, Update on the HIVIAIDS Epidemic and Response in Nigeria. http://naca.gov.ng/content/view/423/lang,en/website.

3. Federal Ministry of Health, Nigeria. 'National HIVIAIDS strategic framework (NSF) 2010-15'. 2012.

4. Nasidi A, Harry TO, Ajose-Coker OO, Ademiluyi SA and Akinyanju OO. Evidence of LAV/HTLV-III infection and AIDSrelated complex in Lagos, Nigeria. Presented at II International Conference on AIDS, Paris 1986.

5. UNAIDS. Global HIVIAIDS Response: Epidemic update and health sector progress towards universal access, Progress Report 2011. 2012.

6. WHO, UNAIDS and UNICEF. Global HIVIAIDS Response: Epidemic update and health sector progress towards universal access, Progress Report 2011, WHO, Geneva, 2011.

7. Anoje C, Aiyenigba B, Suzuki C, Badru T, Akpoigbe K, Odo M, et al. Reducing mother-to-child transmission of HIV: findings from an early infant diagnosis program in south-south region of Nigeria. BMC Public Health 2012; 12:184. doi: 10.1186/14712458-12-184.

8. Chilongozi D, Wang L, Brown L, Taha T, Valentine M, Emel L, et al. Morbidity and mortality among a cohort of human Immunodeficiency virus type 1 -infected and uninfected pregnant women and their infants from Malawi, Zambia, and Tanzania. Pediatr Infect Dis J 2008, 27(9):808-814.

9. Buseri $\mathrm{FI}$, Seiyaboh $\mathrm{E}$ and Jeremiah ZA. Surveying infections among pregnant women in the Niger Delta, Nigeria. Journal of Global Infectious Diseases 2010; 2 (3): 203-211.

10. WHO. 'Antiretroviral drugs for treating pregnant women and preventing HIV infection in infants: Towards Universal Access. Geneva. 2010.

11. Federal Republic of Nigeria: The 2014 Global AIDS Response Program Report (GARPR).2014

12. Imade GE, Sagay AS, Ugwu BT and Thacher TD. Sero- prevalence of Hepatitis B and HIV infection in pregnant women in Nigeria. J Med Tropics 2004; 6(2):15-21.

13. Ajoge HO, Ahmad AA and Lonitola OOS. Trend of human immunodeficiency virus in Okene. J Pure Appl Microbiol 2008; 2:119-124.

14. Buseri FI, Jeremiah ZA and Erhabor O. Prevalence of HIV sero-positivity among antenatal women in Port Harcourt. Trop J Health Sci 2008; 15:55-60.

15. Olokoba AB, Salawu FK, Danburam A, Desalu OO, Midala JK. Olokoba LB, et al. Screening for Human Immunodeficiency Virus Infection amongst Pregnant Women: A Practice that Must Continue. European Journal of Scientific Research 2009; 28: $266-270$.

16. Motayo OB, Okonko IO, Uche LN, Onoja BA and Obiogbolu CH. The Sero-prevalence of Human Immunodeficiency Virus (HIV) among Patients Attending the Special Treatment Clinic at University College Hospital, Ibadan, Nigeria. Nigerian J Microbiol 2009; 23(1): 1904-1910.

17. Ndams IS, Joshua IA, Luka SA, Sadiq HO and Ayodele SB. Human immunodeficiency virus seroprevalence among pregnant women in Minna, Nigeria. Ann Nigerian Med 2010; 4:14-17.

18. Kiptoo M, Mpoke S, Ng'ang'a Z, Mueke J, Okoth F and Songok E. Survey on prevalence and risk factors on HIV-1 among pregnant women in North-Rift, Kenya: a hospital based cross-sectional study conducted between 2005 and 2006. BMC Int Health Hum Rights 2009; 9:10.

19. Urassa W, Kaaya S, Mwakagile D, O'Brien M, Antelman G, Hunter D, et al. Evidence of a substantial decline in prevalence of HIV-1 infection among pregnant women: Data from 1995 to 2003 in Dares Salaam, Tanzania. Scand J Public Health. 2006; 34(3):272-278.

20. Momoh MA and Ezugwuorie OJ. Does screening of pregnant women prevent mother to child transmission of HIV? A study in Nsukka urban area of Enugu State, Nigeria. International Journal of Pharmaceutical Sciences and Research (IJPSR) 2010; 1(1): 1-6.

21. Sahaf F, Tanomand A, Montazam $H$ and Sany AA. Seroprevalence of hepatitis $C$, hepatitis B and HIV and co-infection among pregnant women: A retrospective study in 2006 at Malekan city, Iran. Res J Med Sci 2007; 1:138-141.

22. Todd CA, Ahmadzai M, Atiqzai F, Miller S, Smith JM, Ghazanfar SAS, et al. Sero-prevalence and correlates of HIV, syphilis, and hepatitis $B$ and $C$ virus among intra-partum patients in Kabul, Afghanistan. BMC Infectious Diseases 2008; 8: 119-126.

23. Imade $\mathrm{P}$, Ibadin $\mathrm{K}$, Eghafona $\mathrm{N}$, Enabulele $\mathrm{O}$ and Ophori $\mathrm{E}$ HIV Sero-prevalence among pregnant women attending antenatal clinic in a tertiary health institution in Benin City, Nigeria. Macedonian Journal of Medical Sciences 2010; 3 (1): 43-45.

24. UNAIDS/WHO: Guidance on provider-initiated HIV testing and counselling in health facilities. Geneva: Joint United Nations Programme on HIVIAIDS (UNAIDS) and World Health Organization (WHO); 2007:1-60.

25. UNGASS Country Progress Report: Nigeria. http: www.unaids. org/en/Country/Nigeria.asp. 2010.

26. 'UNAIDS report on the global AIDS epidemic' http: www.unaids. org/globalreport/Global_report.htm. 2010.

27. Ugochukwu EF and Kalu SO. Early Infant Diagnosis of HIV Infection in Southeastern Nigeria: Prevalence of HIV Infection among HIV-Exposed Babies. West African Journal of Medicine 2009; 29(1): 3-7.

28. Audu RA, Salu OB, Musa AZ, Onyewuche J, FunsoAdebayo EO, Iroha EO, et al. Estimation of the Rate of Mother to Child Transmission of HIV in Nigeria. Afr J Med Sci 2006; 35(2):121-124.

29. Okeudo C, Ezem B and Ojiyi E. Mother-To-Child Transmission 
Rate of HIV at Orlu, South-Eastern Nigeria. The Internet Journal of Gynecology and Obstetrics 2012; 16: (2).

30. Tukur J, Galadanci H, Adeleke SI and Mukhtar-Yola M. Outcome of delivery among HIV positive mothers at Aminu Kano Teaching Hospital, Kano. Niger J Med 2007; 16: 34-37.

31. Tornatore M, Gonçalves CV, Mendoza-Sassi RA, Silveira JM, D'ávila NE, Maas CG, et al. HIV-1 vertical transmission in Rio Grande, Southern Brazil. International Journal of Sexually Transmitted Diseases and AIDS 2010; 21:351-355.

32. Núñez IG, Jidy MD and Ávila JP. Vertical Transmission in Cuba. Medicc Review 2006; Vol VIII(1).

33. Odaibo GN, Olaleye DO, Heyndrickx L, Vereecken K, Houwer K and Jassens W. Mother-to-child transmission of different HIV-1 subtypes among ARV naïve infected pregnant women in Nigeria. Rev Inst Med Trop S. Paulo 2006; 48: 77-80.

34. Ogunbosi BO, Oladokun RE and Osinusi KI. Prevalence and clinical pattern of paediatric HIV infection at the University College Hospital, Ibadan, Nigeria: a prospective cross-sectional study. Italian Journal of Pediatrics 2011; 37: 29 doi:10.1186/18247288-37-29.

35. Newell M, Coovadia H, Cortina-Borja M, Rollins N, Gaillard P and Dabis F. Mortality of infected and uninfected infants born to HIV-infected Mothers in Africa: a pooled analysis. Lancet 2004, 364:1236-1243.

36. Tubiana R, Le Chenadec J, Rouzioux C, Mandelbrot L, Hamrene K, Dollfus C, et al. Factors associated with mother-tochild transmission of HIV-1 despite a maternal viral load $<500$ copies/ml at delivery: a case-control study nested in the French perinatal cohort (EPF-ANRS CO1). Clin Infect Dis 2010, 50:585-596.

37. United States Centers for Disease Control and Prevention: Diagnoses of HIV infection by age. 2010. http://www.cdc.gov/ hiv/topics/surveillance/basic.htm\#hivaidsage website

38. Igwegbe AO, Ugboaja JO and Nwajiaku LA. Prevalence and determinants of non-adherence to antiretroviral therapy among HIV- positive pregnant women in Nnewi, Nigeria. International Journal of Medicine and Medical Sciences 2010; 2(8): 238-245.

39. Ekama SO, Herbertson EC, Addeh EJ, Gab-Okafor CV, Onwujekwe DI, Tayo F, et al. Pattern and Determinants of
Antiretroviral Drug Adherence among Nigerian Pregnant Women. Journal of Pregnancy 2012; Article ID 851810, 6 pages http://dx.doi.org/10.1155/2012/851810.

40. Carlucci JG, Kamanga A, Sheneberger R, Shepherd BE, Jenkins CA and Spurrier J. Predictors of adherence to antiretroviral therapy in rural Zambia. J Acquir Immune Defic Syndr 2008; 47 (5): 615-622.

41. Olowookere SA, Fatiregun AA, Akinyemi JO, Bamgboye AE and Osagbemi GK. Prevalence and determinants of nonadherence to highly active antiretroviral therapy among people living with HIVIAIDS in Ibadan, Nigeria. J Infect Dev Ctries 2008; 2(5): 369-372.

42. Shaahu VN, Lawoyin TO and Sangowawa AO. Adherence to highly active antiretroviral therapy (HAART) at a Federal Medical Centre. Afr J Med Sci 2008; 37(1): 29-36.

43. White BL, Wohl DA, Hays RD, Golin CE, Liu H and Kiziah CN. A pilot study of health beliefs and attitudes concerning measures of antiretroviral adherence among prisoners receiving directly observed antiretroviral therapy. AIDS Patient Care STDS, 2006. 6: 408-417.

44. Galli L, Puliti D, Chiappini E, Gabiano C, Ferraris G, Mignone F, et al. Is the Interruption of Antiretroviral Treatment During Pregnancy an Additional Major Risk Factor for Mother-to-Child Transmission of HIV Type 1? Clinical Infectious Diseases 2009. 48:1310-1317.

45. Murphy DA, Roberts KJ, Martin DJ, Marelich W and Hoffman D. "Barriers to antiretroviral adherence among HIV-infected adults," AIDS Patient Care and STDs, 2000; 14 (1): 47-58.

46. Hayman L. "Adherence to antiretrovirals among US women during and after pregnancy" MCN. The American Journal of Maternal Child Nursing 2009; 34 (1): 69. DOI:10.1097/01. NMC.0000343873.33226.92.

47. Palmer NB. "Special group-drug use, mental illness, pregnancy," in Medication Adherence in HIVIAIDS, L. Jeffrey, Ed., Liebert, Larchmont, NY, USA, 2004.

48. Shaffer N, Hedberg K, Davachi F, Lyamba B, Breman JG, Masisa OS, et al. Hightower A, Nguyen-Dinh P. Trends and risk factor for HIV-1 seropositivity among outpatient children, Kinshasa, Zaire. AIDS 1990; 4: 1231-1236. 